\title{
EXPLORING THE EFFECTS OF COGNITIVE BEHAVIOURAL THERAPY ON THE EMPLOYEES WORKING IN THE COMPANIES: THE EFFICIENCY OF CBT ON WORK-RELATED MENTAL HEALTH PROBLEMS
}

\author{
BSc. Irmak ÇAVUŞOĞLU \\ Future Academy, United Kingdom, (irmak.cavusoglu14@gmail.com) \\ Dr. Zafer BEKİROĞULLARI \\ Near East University, Faculty of Arts and Sciences, Cyprus,(dr.psk.bekir@gmail.com)
}

\begin{abstract}
This paper's main goal is to provide comprehensive knowledge about mental health among employees within the workplaces and to discuss how the adverse effects of mental disorder can be addressed through Cognitive Behavioural Therapy (CBT). A Systematic literature review is adapted as a methodology and after evaluating numerous findings, CBT found to be the most effective form of psychotherapy when addressing the work-related mental disorders. In overall, it is suggested that experiencing psychological distress has an adverse effect on employee's physical health and work performance. Work-related distresses can be reduced through CBT as it leads to an affirmative impact on the mental well-being.
\end{abstract}

Keywords: Effectiveness of Cognitive Behavioural Therapy, Cognitive Behavioural Therapy Within Organisations, Counselling Techniques in Cognitive Behavioural Therapy, Mental Wellbeing In The Organisations.

\section{BİLIŞSEL DAVRANIŞÇI TERAPİNIN ŞİRKET ÇALIŞANLARI ÜZERINDEKI ETKILLRININ ARAŞTIRILMASI: BİLIŞSEL DAVRANIŞÇI TERAPININ İŞ İLE ILIŞKINN ZİHINSEL SAĞLIK SORUNLARINDAKİ ETKINLIĞ}

\begin{abstract}
ÖZET

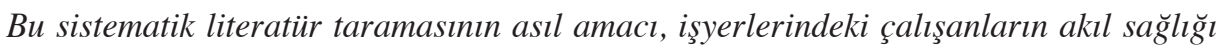
konusundaki bilgi birikimini artırmak ve zihinsel bozuklukların bireyler üzerindeki olumsuz. etkilerini Bilişsel Davranışcı Terapisi ile (BDT) nasıl etkili bir şekilde giderilebileceğini ele almaktır. Literatür taraması ile elde edilen sayısı bulgulara göre, BDT'nin isyerlerindeki çalışanların zihinsel bozukluklarını tedavi etmede en etkili ve en başarılı psikoterapi şekli olduğu kanıtlanmıştır. Bilişsel Davranışç Terapi aracılı̆̆ ile çalışanların işyerlerinde karşılaştıkları, hem fiziksel hem de iş performanslarını olumsuz bir şekilde etkileyen sorunların giderilebileceği kanıtlanmıştır.
\end{abstract}

Anahtar Kelimeler: Bilişsel Davranışç Terapinin Etkinliği, Kurum İçi Bilişsel Davranışçı Terapi, Bilişsel Davranışçı Terapide Danışmanlık Teknikleri, İsyerlerindeki Zihinsel Refah. 


\section{Introduction}

Stress and anxiety are inevitable in today's world. When an individual is stressed, this can cause serious destructive physiological and psychological effects (McEwen, 2000). As McEwen, stated chronic stress cascade has the potential to cause an imbalance in cognition and this could lead to poor decision making, poor mood, and anxiety. Stress can have long-lasting effects on the epigenetic mechanism in humans and the changes in the epigenetic mechanism can shorten the life expectancy by affecting both the brain and the body of individuals (McEwen, 2017). Along with these significant findings, the cascade of stress could be associated with deterioration in memory, performance and attention (Cerqueira et al., 2007).

Psychological distress is a general term used to describe the unpleasant emotions or sensations such as anxiety, sadness, frustration or anger (Pratt, 2009). In recent years, it has been found that psychological distress can even lead to death (Pratt, 2009). It has been also stated that the burden of mental ill health accounts for approximately $14 \%$ of the world's burden of ill health (Rao \& Ramesh, 2015). Employees are more likely to experience psychological distress and it has been reported in Japan, approximately $60 \%$ of the workers experience severe psychological distress associated with their occupations. Furthermore, the number of employees that are experiencing psychological distress has been increased in the past 5 years. The particular reason for this rise is associated with the increased workloads of the employees (Ministry of Health, Labour and Welfare, 2013). Commercial organizations these days are putting more and more pressure on employees by expecting them to perform beyond their capabilities (Cherniss, 1980). Previous research studies have established that the complexities within the organizations are directly related to the stress that is being experienced by the employees (Stelling \& Cherniss, 1982). Unfortunately, the increased number of staff turnover, poor performance, increased sickness absence and increased number of human error accidents in the company are now common especially due to the increase in the individual workload (Reme et al., 2015).

Numerous well-documented research studies have shown that there is a direct association between both physical illness and psychological distress with the working conditions (Clarke, 2004). Nonetheless, this subject has been underestimated and overlooked yet there is strong evidence that supports the relationship between work-related injuries and accidents with the stressful conditions. For instance, the importance of the mental health is being underestimated in the workplaces as the majority of the managers do not think that their employees are struggling with mental illness however, 1 in 6 employees are experiencing it (Rao \& Ramesh, 2015). In the United Kingdom, every single organisation is being affected by the mental health problems within the workplaces. It has been argued that one in six workers are experiencing disorders such as depression, anxiety or stress-related problems (Mental Health at Work: Developing the business case, 2007). Thus, mental distress occurs in every organization and it should be considered as a normal issue. While considering this as a normal issue, an action should be taken in order to prevent any tragic results. Evidence shows that even car drivers of the companies (Cartwright et al., 1996), and transit operators (Leitão \& Greiner, 2015) could be affected by these conditions. 
According to Mental Health at work, 2007's records, in the UK, the total economic burden of mental ill health is estimated about 26 billion pounds in each year and this number is equivalent to 1,035 pounds for every single employee in each year. In addition, according to the evidence, it has been suggested that the key component of a good business is having a better understanding and management of mental health as substantial costs could be avoidable by taking an effective action (Mental Health at Work: Developing the business case, 2007). Due to these records, recruiting a therapist for the workplace would be much more cost effective for the company. The reason for this is, anxiety, stress and depression cost for every single employee approximately 1,149 pounds per year (Mental Health at Work: Developing the Business Case I ENMHP, 2019)

There are numerous reasons why caring the mental health condition of an employee would be cost-effective and productive for the businesses (Mental Health at Work: Developing the business case, 2007). The effects of mental ill health of employees on the business are multiple. One of them is the association between absenteeism from work and mental ill health for which many do not take any action to prevent or measure it accurately. The second effect is an impaired performance, which is not normally attributed to mental distress. Another main consequence for the organisations might be the increased number of staff turnovers. In developing societies, the association between psychological well-being and stress has started to gain more and more academic interest with the increased numbers of psychological distress and work-related injuries. Therefore, psychological interventions to ameliorate stress could prove to be beneficial in stress management and employee performance optimization. Cognitive Behavioural Therapy (CBT) is one of these interventions. CBT is a form of psychotherapy treatment approach, pioneered by Aaron Beck and Ellis. CBT could have its places within the organizations for both the company's and employee's own good. In this therapy approach, underlying reason of both the psychological distress and mental disorders shares the same basic cause; this cause being the cognitive distortions of an individual (Hofmann et al., 2019). As stated by the pioneers of CBT, Beck and Ellis, how an individual thinks affects the way they feel and behave. Individual's thoughts, feelings and actions are all interconnected with each other and they are continuously affecting one and other like a vicious cycle (Beck et al., 2016). In this sense, having maladaptive cognitive distortions make the conditions conducive to the maintenance of emotional distress and behavioural problems (Hofmann et al., 2019).

Thus, this review's main goal is to increase awareness and knowledge about mental ill health among employees within the workplaces and to discuss how the adverse effects of mental disorder can be addressed by CBT.

\section{Objective}

In this article, it is aimed to conduct a systematic literature review on the subject of Cognitive Behavioural Therapy within the organisations. Effectiveness of applying the Cognitive Behavioural Therapy to the employees is explored briefly. Applicability of CBT as a psychotherapy treatment within the organisations for numerous psychological disorders and the future improvements in this particular field is examined. In summary, this study is designed with the purpose of clarifying some important issues in this area: 
- The relationship between Cognitive Behavioural Therapy and organisations,

- The effect of psychological disorders on the work performance,

- The efficiency, applicability and use of Cognitive Behavioural Therapy within the workplace,

- Counselling intervention techniques of Cognitive Behavioural Therapy and

- The future improvements in this field.

Therefore, this study looks at the efficiency and effectiveness of Cognitive Behavioural Therapy for work-related mental ill health problems.

\section{Scope}

This study intends to explore all the feasible impacts of Cognitive Behavioural Therapy within an organisation. It is mainly intended to answer the question of "Does a cognitive behavioural therapist have a place within the companies?" by synthesizing relevant information from numerous well-documented researches on this field.

\section{Justification of The Study}

Recently, numerous studies have been explored the impact of work-related stress on the mental health condition. Majority of these studies tackled the occupation-related mental health disorders by using Cognitive Behavioural Therapy. It is crucial to acknowledge that stress and anxiety are inevitable in today's world and employees are constantly experiencing stress due to their burden of work. Therefore, this systematic literature review was aimed to explore the efficiency of Cognitive Behavioural Therapy on work-related mental disorders. Cognitive Behavioural Therapy is a psychotherapy that is being widely used to treat numerous mental disorders (Bekirogullari, 2018), and it can prove to be effective in decreasing work-induced mental ill health

\section{Methods}

\subsection{Literature Searches}

The keywords that have been used during the selection of literature are as follows: "effectiveness of cognitive behavioural therapy, Cognitive Behavioural Therapy and the organisations, counselling techniques in cognitive behavioural therapy, and mental wellbeing in the organisations"

\subsubsection{Selection of Studies}

While selecting the literature, the crucial determinant was the compatibility of the study. While carrying out research, the reliability, validity and the timeline of the study were key factors. It was crucial to include recent studies as they are the ones that show eliable present findings. Several studies were found by using topic-related keywords. The scope of the studies was evaluated carefully and only the most relevant materials were included. 


\subsubsection{Systematic Review Procedure}

To be able to achieve reliable and valid outcomes, a systematic research review has been carried out for this particular topic. The studies were selected based on their context and selected studies were in the structure that allowed the writer to examine the effectiveness of Cognitive Behavioural Therapy on work-related mental health disorders by analysing and synthesis the literature During the research, appropriate keywords were used to find out the previously published literature.

\section{Cognitive Behavioural Therapy}

The past 20 years has been the most exciting years for advances in Cognitive behavioural therapy. Research studies show that CBT has been the most popular choice while treating the various psychological disorders as this therapeutic approach is not only used for reducing and alleviating individual's sufferings but also used to maintain the well-being that individuals achieve by getting this therapy (Beck et al., 2016). Mental health disorders affect approximately 500 millions of people worldwide and every 1 in 6 individuals are suffering from mental health or a neurological disorder (Rao \& Ramesh, 2015). 20\% of adolescents experience mental health problems and 50 per cent of these mental health problems are established by the age of 14. Unfortunately, 70 per cent of individuals have not had any appropriate mental health intervention (World Health Organization). The main goal of CBT is to diminish the dysfunctional thoughts (the thoughts that affect an individual's feelings and behaviours). CBT argues that every individual which suffers from mental health disorder has these dysfunctional thoughts. Beck, the pioneer of CBT, argues that cognitive factors maintain psychological distresses and the maladaptive cognitive distortions contribute to the maintenance of psychological disorder (Hofmann et al., 2012). The word of maladaptive cognitive distortions refers to schemas, general beliefs about one's self, others around them, their world and how they perceive the future. By applying CBT, the main goal is to apply various different therapeutic strategies to alter the cognitive maladaptive distortions in order to create both emotional and behavioural changes (Hofmann et al., 2012). Therefore, the main aim of a Cognitive behavioural therapist is to assist individuals to manage their overwhelming and devastating problems in a more realistic and positive way by dividing them into smaller parts. Thus, individuals can experience improvements when they learn to evaluate their thoughts in a more realistic and positive way (Beck et al., 2016).

Cognitive Behavioural Therapy has several key principles. Firstly, CBT is a standardised approach that is always based on the individual formulation of the patient's problems and to the conceptualising of every patient in the cognitive terms. Secondly, to be able to sustain an effective therapy, the therapeutic relationship between the patient and the psychologist is very crucial. Cooperation and active participation of the patient is another key factor as CBT is like teamwork. In this sense, the therapist and the patient decide everything about the sessions together. By this way, everything is agreed by the patient and this is an important factor that increases the efficiency and the effectiveness of the sessions. In the beginning, CBT always emphasizes the present moment as this makes CBT tbe a goal oriented, time-limited and problem-oriented approach. That is to say, from the be beginning of the sessions, problem that the patient is suffering from, the goals they want to achieve is specified thus, both the therapist 
and the patients can set their individualized goal. This therapy teaches patients how to identify, evaluate and respond to their dysfunctional thoughts by using various different techniques to alter the thoughts, emotions and behaviours. Cognitive Behaviour Therapy is an educational therapy as it teaches the clients to be their own therapist in time in order to prevent the relapse (Beck, et al., 2016).

Unlike other approaches, it is a shorter-term therapy that lends assistance to people to alter their maladaptive behaviour by changing thinking patterns. This means that CBT does not pay attention either to the cause or to the background of the problem but only pay attention to the way of perceiving and intervening the problems. This is why CBT is a very effective method as focusing on the present moment problems and possible solutions make CBT, both cost effective and time effective approach.

It is important to note that, the aforementioned main principles are valid for every single patient. The fact remains that, the therapy can differ by the nature of a patient, life and developmental states, mental level, gender, culture (values \&norms). Taking into account all of these, the CBT is an individualized approach and yet there are some key principles that underpin this therapeutic approach (Beck, et al., 2016).

\section{Relationship Between Cognitive Behavioural Therapy and Organizations}

Sustaining motivational ambience in a workplace is crucial as it can be used to foster the therapeutic alliance (Holtforth \& Castonguay, 2005). According to the theory of consistency (Grawe, 2004), human beings seek to get the fulfilment of their psychological needs. According to the Epstein's (1990) theory of "cognitive experiential self-theory", there are five main psychological needs that human beings strive to achieve, and these psychological needs are proposed to be as follows: control, orientation, pleasure, self-attachment and attachment. Developing motivational goals are important as they might be the key aspects of gratifying and satisfying one's psychological needs. As a result, fostering symptom reduction and improving both physical and psychological wellbeing's central mechanism is to improve the need satisfaction (Holtforth \& Castonguay, 2005). In the context of psychotherapy, improving need satisfaction and motivational attunement can be done by CBT. It is important to note that, CBT is not the only way to improve however the focus of this review is on CBT as it proposes to be a both cost-effective and time effective approach (Beck, et al., 2016). Besides, the concept of "motivational attunement" is mainly based on CBT (Grawe, 2004) and this concept has been grown out of the cognitive-behavioural tradition (Grawe \& Dziewas, 1978).

Cognitive Behavioural Therapy is not psychotherapy that can be only delivered in private settings. As it is mentioned earlier, Cognitive Behavioural Therapy can be used effectively to treat a variety of psychological disorders as it is an educational approach and long-lasting psychotherapy (Bekirogullari, 2018). Thus, Cognitive Behavioural Therapy should have their places within the organizations in order to energize and empower the employees to work and deliver a better job at their working places by providing the required support.

Some individuals might have a goal system that is maladaptive. In such occasions, the psychological needs could be compromised of maladaptive behaviours and strategies which in turn these can affect that individual and people around them in a negative manner. 
These maladaptive behaviours and strategies may enable to accomplish some needs in the short term however, it may endanger other needs in the long term (Holtforth \& Castonguay, 2005). For instance, a narcissistic individual may constantly boast about his/her achievements and this can encourage and promote his/her self-esteem by perceiving herself/himself better than anyone. In this sense, this behaviour can be seen as fostering that specific individual's psychological needs however in a broader context such behaviours may result into conflicts within a workplace by hampering his/her human relations (Holtforth \& Castonguay, 2005). In a corporate company, it is important for every single employee to feel valuable, equal and be treated fairly. Thus, in the presence of such maladaptive behaviours can result in conflicts, could increase the burden of work and in turn increase the work-related psychological distress. Cognitive Behavioural Therapy is one of the best approaches to annihilating these maladaptive behaviours by establishing a solid therapeutic bond and contentful intervention strategies. Consequently, recruiting a cognitive behavioural therapist has a potential to energize and empower the company workers A cognitive behavioural therapist can work efficiently with issues related to depression, anxiety as well as a CBT therapist can increase the efficiency of the employees, lessen the absent days that employees spend off the work (Rao \& Ramesh, 2015).

\section{Previous Literature}

The working conditions and mental health of employees have a quite complex relationship (Rao \& Ramesh, 2015). It is accurate to say that, working and being productive has a positive impact on one's mental health as it helps to acquire the concept of job security, time management, social contact and good organizational abilities. These are the factors that can elevate an individual's well-being (Harnois \& Gabriel, 2000). However, experiencing chronic stress at work can affect the mental health of the employees adversely, and this can disrupt work (Rao \& Ramesh, 2015). Experiencing such conditions can lead to a decrease in the productivity of the employees, increase the number of absenteeism rates, can affect the profit margins and can bring extra costs to the company (Rao \& Ramesh, 2015). In the literature, there are a few works of literature that have looked specifically to the association between Cognitive Behavioural Therapy and its places within the organizations. Even though it has received less academic attention, there are well-documented researches that provides evidence supporting the association between work-related incidences and working conditions (Clarke \& Cooper, 2004).

As stated by the California Labor Code, the employees have right to indemnity for illness or disability caused by "constant physically or mentally traumatic events extending over a period" and has the right to compensation if the combined effect of these causes any dysfunctions or any need for medical treatment. Furthermore, the importance of work-related personal injuries gained great attention from the landmark case of Walker vs Northumberland County Council (Clarke \& Cooper, 2004).

There is a term which highlights the importance and existence of chronic interpersonal stressors within the workplace. According to the previous literature the term "job burnout" refers to the psychological syndrome as a response to work-related personal chronic stress cascades (Stelling \& Cherniss, 1982). Regarding this, there are three main key features of this response; feelings of detachment and cynicism from the job, exhaustion, sense of inefficiency 
and lack of accomplishments. The cynicism component is also known as depersonalization and it represents the interpersonal aspects of the burnout as it attributes to extremely negative detached response to the various dimensions of the job. The concept of exhaustion refers to the core and the basic personal stress aspect of burnout. An individual who is exhausted may experience the feeling of depletion both emotionally and physically and this can continue for a long period of time (Stelling \& Cherniss, 1982). Lastly, the sense of inefficiency and/or lack of accomplishments component refers to the self-evaluation aspects of the burnout. An individual who is feeling inefficient tend to evaluate themselves more cruelly and may experience the sensations of incompetence and insufficiency. Thus, one's productivity can diminish. The concept of job burnout is highly associated with the job performance as it is argued that the reason of absenteeism, job withdrawal, intention to leave the work, resigning and turnovers is the occupational stress (Stelling \& Cherniss, 1982). Furthermore, it was also suggested that, for the employees that continue to stay in the job, their personal and interpersonal relations could be aggravated as their effectiveness and productivity could be lowered. Additionally, individuals who are experiencing burnout may have more interpersonal conflict as the signs of their burnout may affect their colleagues negatively. As a result, burnout could be contagious and these can lead to less job satisfaction and less productivity for the organization (Stelling \& Cherniss, 1982). Besides these, there is some evidence which claims that the concept of burnout has the potential of negative spillover effect on their individual's private lives (Burke \& Greenglass 2001). As emphasised throughout this paper, work-related stress cascades and mental health condition is highly related to each other (Stelling \& Cherniss, 1982). Although mental health is complex, it was supported by several lines of evidence that experiencing burnout as a result of working conditions is a form of mental health problem. Experiencing burnout may lead to the development of mental dysfunctions such as depression, anxiety, low self-esteem and so on, on the individuals. Therefore, as emphasised earlier, Cognitive Behavioural Therapy is one of the best psychotherapies that can be used as a treatment for mental dysfunctions (Stelling \& Cherniss, 1982).

In order to assess the effectiveness of Cognitive Behavioural Therapy on occupational stress, four meta-analyses: were examined intensively. According to the results, the majority of the outcomes were quite similar. The results showed that cognitive behavioural interventions were much more effective in treating mental dysfunctions than any other intervention approaches (Hofmann, et al., 2012). For instance, organizational focused interventions and cognitive behavioural therapy's interventions were compared and it was supported by this unique study that CBT was more effective as it focused on psycho-social outcomes in the employees (Richardson \& Rothstein, 2008). Richardson \& Rothstein (2008) has shown that applying CBT alone as stress management is more effective in comparison to applying a combined approach such as CBT combined with another psychological component. Another study done by Reme, et al., (2015) aimed to evaluate the effectiveness of work-based Cognitive Behavioural Therapy and the necessary supports were given for the individuals who were struggling with participating in work due to mental health disorders. It was concluded by this study that, individual work-based Cognitive Behavioural Therapy was found to be more effective and efficient compared to the usual treatment. Positive impacts of work-focused CBT were profound for employees in the long term. It was stated by Srivastava, 2009, that the productivity and efficiency of employees are directly related to mental health. Individuals tend to be more efficient and productive in the mentally healthy workplaces (Srivastava, 2009). 


\section{Intervention Techniques in Cognitive Behavioural Therapy}

Cognitive Behavioural Therapy is a single approach that employs a broad range of approaches that are consolidated by several underlying principles (Beck, 1995). Thus, what makes CBT effective is the unification and presence of these numerous principles. Elementarily, establishing a therapeutic relationship between a client and the therapist is extremely important as this bond will allow the therapist to enhance the principles of CBT into practice (Johnstone \& Dallos, 2006). Additionally, another important principle to consider is to the formulationbased cognitive and behavioural theory to understand and conceptualise the patient's presenting problems. Another principle is to build collaborative empiricism (Beck, 1995), which means conceptualising the problem by understanding briefly what has caused it and what is maintaining it. Whenever such collaboration is well established, the therapist and the client can work cooperatively. Working cooperatively with the client allows the therapist to build up the formulation successfully. As the formulation of a client should be build up layer by layer during the therapy sessions (Kinderman \& Lobban, 2001). Assembling a literal formulation is crucial because a clinical work experience may lead the therapist to hypothesise the cause and reason factors of the problems, however a therapist can't be sure about their hypothesis until the client tells if it is relevant for them or not (Johnstone \& Dallos, 2006). Another crucial principle of CBT is to build up a general framework of the intervention planning by considering the agreed goals of the client.

Cognitive Behavioural Therapy allows the therapist to formulate and conceptualise the client's problems effectively by providing a rationale for choosing from the large and complex spectrum of interventions (Needleman, 1999). Identifying cognitive and behavioural underlying mechanism is essential as this will provide a literal understanding of the problem and will lead the therapist to choose the appropriate intervention techniques (Johnstone \& Dallos, 2006).

Nowadays, regarding the formulation process of CBT, it is important for a therapist to built-up the framework of the patient based on the five Ps rule. According to this five Ps, the presenting issues, precipitating factors, perpetuating factors, predisposing factors and protective factors are crucial key to gather a better outcome from the therapy sessions and enable to achieve the goals of the patient. To be able to examine these factors, the therapist should listen to the patient's words clearly, attentively and ask relevant particular questions sometimes by using the Socratic method (Beck, et al., 2016).

For instance, $\mathrm{ABC}$ model is one of the intervention techniques that can be used by the therapist to explain the interaction between thoughts, feelings and behaviours and help the therapist to uncover the P factors efficiently (Johnstone \& Dallos, 2006). In general, ABC is a question guided method that encourages the patient to look from other perspectives thus, it enables them to realize that seeing a situation in a specific way and the thoughts are not always reflective of the real facts or truths. Thus, by this method thinking about other possible facts and thinking about how others would react differently to the exact same situation is a good way to show the negative automatic thinking patterns to the patient. Generally, ABC is one of the first steps that the majority of the patients realize their negative automatic thoughts and they become more aware of the fact that their dysfunctions arise from their automatic thinking patterns. By using this method, it becomes easier to illustrate the importance and impact of 
negative thoughts on one's feelings and behaviours. Identifying the impact of present issues and precipitating factors on one's psyche is important to outline how each relates to each other. Another advantage of using the ABC model throughout the sessions is the fact that this method enables the therapist to easily introduce the personalised and specific examples of the patient's experiences. In this sense, it provides a good method to show the patient the fact that there might be different ways of perceiving the issues (Johnstone \& Dallos, 2006).

As mentioned before, the $\mathrm{ABC}$ method is mostly being used to simply show the interaction between thought-feeling-behaviours and to create awareness about one's negative automatic thoughts. However, only using this method would not be enough to identify the perpetuating factors as $\mathrm{ABC}$ does not specifically explain what maintains and keeps the problem going especially in the long term (Johnstone \& Dallos, 2006).

In such situations, it is better to draw and built-up an extended individual formulation model which is presented by the patient to understand the reason for maintenance of the problem. Usually, a good therapist tends to draw an extended model in a circular way as this shows the associations between the patterns more clearly. Using an extended cross-sectional method is crucial as it contains more explicit and detailed information especially about one's physiological responses to a particular situation (Greenberger \& Padesky, 1995). In order to draw a cross-sectional framework, journalising method can be used. For instance, journalising gives information on the mood of the patient, the specific response to the situations and the underlying sources of the thoughts, feelings and behaviours (Beck, et al., 2016). Additionally, the difference between facts and opinions should be thought to the patient. This means being able to distinguish the fact that thoughts are not FACTS. Majority of individuals tend to believe that what they think reflects the real facts about a situation. However, this is not the case for most of the time and cognitive distortions arise from this way of thinking. Thus, teaching individuals the difference between facts and opinions is of paramount importance (Beck, et al., 2016).

There are many core cognitive and behavioural mechanisms that may include the avoidance behaviours and these may be the key to the maintenance of a psychological disorder (Harvey et al., 2004). Identifying the avoidance behaviour of the patient is another important perpetuating factor in Cognitive behavioural therapy. It is crucial to identify because these avoidance behaviours may provoke the dysfunctions in the long term. Individuals tend to have avoidance behaviour as they think they can prevent themselves from finding in a situation that they are afraid of to be. However, by avoidance behaviours, this may lead to having more unrealistic negative automatic thoughts about one's self (Harvey et al., 2004). Furthermore, it has been proposed that avoiding situations might lead to loss of pleasing, gratifying and rewarding behaviours so this lead to preserve the disorders such as agoraphobia, depression or anxiety.

Therefore, unrevealing cognitive distortions are crucial as the patient should be aware of their dysfunctional distortions to be able to change them with the functional ones. Once the patient learns to reveal their cognitive distortions a cognitive reconstruction technique can be used as a challenge for themselves. If this technique is used at the right time this can help the patient to reconstruct their beliefs. 
On the other hand, some individuals tend to have safety behaviours which means engaging in particular behaviours that will keep them safe (Salkovskis et al., 1996). These behaviours are being done by the individuals with the intention to avoid the undesired events to happen. Paradoxically, like other factors, having safety behaviours increases the likelihood of maintaining the problem. Thus, careful assessment is needed to be done in order to identify these behaviours as these behaviours are detrimental to one's psyche and even worsens the problem. Once they are identified, then the therapist can choose the right intervention techniques to diminish these factors (Johnstone \& Dallos, 2006).

Different from the aforementioned behaviours, there is a broad range of cognitive processes that also plays a role in sustaining the emotional problems. For instance, some of these cognitive processes are; extreme all or nothing thinking, rumination, dissociation, memory impairments and over-generalization (Harvey et al., 2004). Cognitive behavioural model is efficient and effective because it contains a valuable number of interventions which specifies the association between thought, feelings and behaviours (Beck, et al., 2016). Clearly identifying the relationship between these elements increases the efficiency of this model as even only changing in any of these elements can lead to change in the other elements. Thus, one of the important interventions in the CBT is to teach the CBT to the patient first. If an individual becomes aware of the association then they can learn to identify and evaluate and challenge their own cognitive distortions (e.g. over generalization). This means that, if an individual learns to identify, evaluate and challenge their distortions, they can be able to notice and think about a situation in a different way, then they will be more likely to feel and behave in a completely different way. However, for some clients primarily trying to change their thinking patterns may not be the right method to start with. In these situations, the therapist can change their strategy and may try to change the behaviour of the client via behavioural methods. By changing the behaviour, the client will realize that the feeling and thought will be changed accordingly. Thus, CBT is not a one-way approach. CBT can be effectively used by the professional therapist when the therapist knows the features of the client's and what will work for them effectively. For instance, a behavioural experiment can be used to increase the behaviours that are pleasurable and rewarding for that specific individual. This will create positive reinforcement for them as behaving in a pleasurable way can have the potential to increase a sense of mastery in individuals who are diagnosed with depression. Additionally, changing the behaviours may help individuals to develop healthy behaviour patterns that can replace the safety behaviours or avoidance behaviours (Johnstone \& Dallos, 2006).

Even though aforementioned models such as $\mathrm{ABC}$ and cross-sectional models are effective in helping to understand the underlying reason of the problem, it may not give a clue about what is the main reason that led the problems to arise. Identifying predisposition factors of the problem can be crucial sometimes as it introduces the notion of the longitudinal reason for the triggers to the problems (Johnstone \& Dallos, 2006). This is crucial especially when the patient struggles to change their dysfunctional thoughts or behaviours. Typically, understanding that individual's stressors and formulating the intervention model based on this knowledge can give the therapist a strategy to concentrate on.

In regards to the specific intervention techniques that CBT offers, thought records, mastery records, pleasured activity planning, rational responding inventories are the most 
popular ones. The therapist may use them when it is necessary as a practice for the client. Before giving these like homework, the usefulness of these inventories is described to the client. It is also useful for the client as it gives a chance to them to evaluate their thoughts, feelings, and behaviours towards a situation after some time. Moreover, identifying the protective factor is crucial for identifying other factors. These factors tend to be the factors that guide the interventions and have the potential to make the patients feel good. It is important to reveal the good qualities of the patient. These factors can be used effectively as it encourages, boosts the self-esteem, increases the mood and decreases the stress level of the patient after a while. Pleasant activity scheduling is a method that can be used to increase the mood (Beck, et al., 2016).

For the majority of individuals, their negative automatic thoughts are in a form of cognitive/mental images, not in the form of thoughts (Beck, et al., 1985). However, these cognitive images tend to be negative for most of the time thus, conceptualising the images of the patient is one of the most efficient technique in CBT. Doing Imagery based exposure is very useful especially when the therapist can guide the patient well in order to reconstruct those images in their mind. To be able to gather a good outcome, it is important to reconstruct these images positively.

Majority of the CBT techniques are mentioned in this review. In this section, the techniques will be presented briefly. For these extra techniques, the principle is exactly the same as with the core ones.

Individuals may also experience real-life problems related to their psychological disorders. Questioning the source of the problems, identifying the skills that they used to solve the problems and guiding them to find the best possible solution to their problems efficiently is important. However, some individuals are not good at problem-solving. Thus, educating them in the skills of problem-solving could be beneficial. By using "problem-solving analyses form" the patient can be educated in the area of finding alternatives to solve the problems, applying the solution, evaluating the effect and the impact of that specific solution (D'Zurilla \& Nezu, 1990). Moreover, the decision-making ability can be inadequate in many patients. When it is necessary, teaching them to list the possible advantages and disadvantages of each decision and then evaluating each to give the best decision can be adventitious.

In regards to the aforementioned CBT techniques, CBT can be used effectively in workplaces to address issues such as poor problem solving, poor decision making, depression, anxiety and so on (Stelling \& Cherniss, 1982). Additionally, individuals choose to define themselves by what they do and the work they do can refer their social identity because organizations are mostly being used by individuals to build up their sense of self (Weinberg \& Doyle, 2017). In order to build up a healthy sense of self, individuals seek to have well-designed work conditions and to ensure these, cognitive behavioural therapist should have their places within workplaces. Even though, engaging in work can be beneficial for individual's physical health and good work conditions can foster the psychological wellbeing, a poorly designed and organized workplaces have the potential to create mental health problems (Weinberg \& Doyle, 2017). 
In general, to be able to increase the efficiency and effectiveness of a company, the system within the company should be considered as a puzzle and the power of one's psyche should not be underestimated. The success of an organization can be seen as a puzzle as only recruiting a highly qualified employee for a specific occupation is not the only element to gather high productivity rates. Thus, if the managers want to increase the productivity of their organizations, they also have to focus on to the further pieces of the puzzle such as ensuring good work conditions and considering the psychological well-being of the employees. Changing the behaviour of employee's within an existing organization is a crucial element of the puzzle to solve and overcome the aforementioned problems such as job burnout.

The quality and the quantity of support is important for the employees (Madill, 2017). For instance, feedbacks that are given by the therapist should focus on encouraging the employee to exhibit a better performance by setting realistic sets of goals (Madill, 2017). It is important to set realistic goals because if the goals are not being met by the employee, this can reduce their self-esteem (Beck, et al., 2016). Thus, it is important to specify to the employee that setting unrealistic goals are not helpful for their mental health so, the importance of setting realistic, measurable goals is important. Thus, while goal setting, the targets should be specific, accurate, realistic and should enable to measure the performance of the employee. In addition, setting these goals in a realistic time frame is also crucial as it shows the improvement of the patient. Furthermore, necessary skills training should be done for each individual. For instance, the importance of one performance goal at a time should be mentioned. This is crucial because setting specific goals at a time will allow the individual to manage their priorities, will enhance self-esteem, confidence, motivation and will enable them to see their success in a short period of time (Madill, 2017).

\section{Impact of Cognitive Behavioural Therapy on Employees}

Existing experimental studies explored the effectiveness of Cognitive Behavioural Therapy on the employees within the organisation settings. The effectiveness of CBT was examined to see whether psychological distress can be lowered by the interventions of CBT or not. The question of whether the cognitive behavioural therapist has their places within the companies or not was examined carefully by the previous empirical studies.

Four meta-analyses were carried out to examine whether CBT is effective or not in the occupational organizations and it was found out that, CBT is the most effective type of intervention when compared to the other intervention types. CBT was found to be very effective especially in the field of psychosocial outcomes in employees (Richardson \& Rothstein, 2008). In this study, data from 11 different studies were compared between CBT approach and other approaches or control groups. Within these empirical studies, seven out of eleven showed higher response rates for CBT than other treatments. General stress, anxiety disorders, and anger control problems were some of the strongest problems that CBT showed a substantial efficiency in tackling. Additionally, CBT was found to be the most effective way to teach individuals how to manage stress. However, only one of the studies showed that CBT has a lowered response rates when compared with the other treatments (Hofmann, et al., 2012). Thus, Cognitive Behavioural Therapy can be used effectively within the organizational settings in order to treat mental dysfunctions and to provide a better/healthier life to the individuals. 
Additionally, according to another study done by (Takechi et al., 2015), it was supported by the empirical evidence that a 10-week CBT based programme has increased the amount of daily physical activity of the employees and has mitigated the psychological distress of healthy employees. Even though the difference was not found to be significant, it was indicated that the alcohol digestion amount has been decreased and the working hours of the employees have increased. Thus, these results clearly indicated that a CBT-based treatment programme can be used effectively to gather positive mental health a physical health condition.

To conclude, the effectiveness of Cognitive Behavioural Therapy on employees working within a company is proved by well-developed studies. The positive and negative impact of Cognitive Behavioural Therapy on employees will be critically discussed in the below sections. However, additional research studies are needed to be done to also examine any possible negative impacts of this approach (Hofmann, et al., 2019).

\section{Positive Impact of Cognitive Behavioural Therapy on Employees}

The economic cost of mental ill health at workplaces are declared as 8.4 billion pounds absence due to sickness, 15.1 billion pounds due to reduced productivity at workplaces and 2.4 billion pounds are being used up/spent to replace a staff who quit from their jobs in one year because of mental ill health reasons (The Sainsbury Centre for Mental Health). Thus, action should be taken in order to improve the management of mental wellbeing within the organizations. Simple steps such as including a Cognitive behavioural therapist in the workplace can reduce the business cost of organizations and increase the productivity, efficiency and effectiveness of the companies. On this basis, creating awareness about the importance of mental well-being is crucial to turn the management and the development of the businesses to a better. Helping those who are experiencing distress, supporting the employees to be better will be better both for organizations and for the personnel.

Evidence suggests that preventing mental health problems that are directly work associated, creating awareness, increasing their knowledge and understanding of mental health issues among the employees are the key factors in an effective work organization (The Sainsbury Centre for Mental Health).

According to an empirical study done by Takechi et al., 2015, there was a significant decrease in the psychological distress after the cognitive behavioural intervention; $64 \%$ of the participants reported the interventions as positive and effective for their health. During this study, dysfunctional mental thoughts such as over generalization or dysfunctional behaviours were prevented by exercising and then corrected by the help of daily basis exercises. Additionally, positive effects promoting goal achievement and behavioural changes were noted (Harkin et al., 2016). In addition to these, a CBT based wellness programme for employees was created and consequently, improvements were reported in the activity of the personnel and in the health-related quality of life (Edries, et al., 2013). In this particular programme, it was not only CBT- exercise-based programme but was a programme based on to promote and improve the self-efficacy of the employees. Employee's abilities of pacing, goal setting and self-reflection was aimed to improve. The outcomes of this study were gathered by answering open-ended questions and it was evidenced that behaviours of the personnel were changed positively and this program was effective to address the maladaptive thoughts. 


\section{The Negative Impact of Cognitive Behavioural Therapy on Employees}

Creating a stable and mentally healthy environment in the workplace can boost the efficiency and productivity of the employees (Rao \& Ramesh, 2015). However, the business owners might have some concerns about whether recruiting a cognitive behavioural therapist within the workplace have any negative impact on the working system of the company or not. Regarding this, any possible adverse effect of recruiting a therapist will be briefly discussed in this section.

Firstly, it has to be mentioned that, the number of individuals who experience mental ill health problems are increasing every single day (Ministry of Health, Labour and Welfare, 2013) In this sense, having a mental disorder should not be regarded as something to be ashamed of and should have the equal value as having physical ill health. The concept of mental disorder can differ across cultures and in some cultures this may be seen as a normal issue but in other cultures, it may not. Thus, a possible adverse effect could be the fact that the individuals who wish to get professional help from the company's psychologist may be stigmatised by his/her colleagues. Being stigmatised by others may create even more fear and social detachment (Angermeyer \& Matschinger, 2003). However, this issue should not be an excuse to exclude a therapist within the company settings. In this case, according to Robinson (2009), the importance of mental health should be communicated to the society and mental illness should be acknowledged as a bona fide illness by the society. The first possible solution to reduce the stigmatisation is through increasing the understanding and creating awareness in the society (Robinson, 2009). Creating awareness about the extensity of mental disorders and establishing the acceptance of mental disorder should be the key components to deal with stigma and labelling issues.

As it has been emphasised throughout this review, the number of individuals who suffer from mental ill health is increasing every single day (Ministry of Health, Labour and Welfare, 2013). Thus, an individual's mental ill health problems are actually a whole population problem and it is widespread. Therefore, ignoring this vital problem is not the solution and ignoring this issue would be unethical, inappropriate and irresponsible (Mental Health at Work: Developing the business case, 2007)

\section{Conclusion}

Over the last decade, it has been demonstrated by numerous studies that teaching cognitive behavioural techniques are effective for managing the stress of individuals and effective in reducing the work-related stress (Takechi et al., 2015). It has also been indicated that the best approach to tackle the work-related mental health disorders is Cognitive Behavioural Therapy as this therapy found to be more effective than other conventional approaches. CBT was more effective in increasing the productivity of an employee, in maintaining the work participation and reducing the absenteeism for individuals with common mental disorders (Lagerveld, et al., 2012). It has also been suggested that the Cognitive Behavioural Therapy provides longlasting impact than other conventional interventions (Reme, et al., 2015). The economically productive population is also a healthy population. Thus, the implementation of Cognitive Behavioural Therapy in a workplace will develop the company, improve both physical and 
psychological health of employees, increase the productivity and efficiency of the company. Most importantly, it will enhance the mental well-being of the whole community as it has been proved that health promotion intervention such as CBT leads to an affirmative impact on mental well-being (Graveling, et al., 2008). Thus, psychological distress associated with work can be reduced through Cognitive Behavioural Therapy (Takechi et al., 2015). In this sense, CBT should have their places in the organizations because contrary to what is believed, recruiting a CBT therapist would not cost much for the company vice versa it would be costeffective for the good of the company.

\section{Future Direction}

The main recommendation of this systematic literature review is to run more research in order to improve the evidence on this very important topic. The reason for this is, the mental health disorders are not only an individual problem as it is a major problem for the business owners or stakeholders (Reme, et al., 2015). Carrying out long-term follow-up sessions and further study trials will offer more evidence and insight into this topic. Rapidly increasing number of studies have shown that Cognitive Behavioural Therapy could be a viable and effective method in order to reduce the work-related mental ill health problems (Reme, et al., 2015).

\section{References}

Angermeyer, M., \& Matschinger, H. (2003). The stigma of mental illness: Effects of labelling on public attitudes towards people with mental disorder. Acta Psychiatrica Scandinavica, 108(4), 304-309.

Beck, A., Rush, A., Shaw, B., \& Emery, G. (1985). Cognitive therapy of depression .

Beck, J., Şahin, M., \& Tarı Cömert, I. (2016). Bilişsel davranış̧ı terapi.

Bekirogullari, Z. (2018). Cognitive Behavioural Therapy in treating persons with learning disabilities. Journal of Educational Sciences \& Psychology, 8(2), 31-39.

Clarke, S., \& Cooper, C. (2004). Managing the risk of workplace stress: Health and safety hazards. Routledge.

Cerqueira, J., Mailliet, F., Almeida, O., Jay, T., \& Sousa, N. (2007). The prefrontal cortex as a key target of the maladaptive response to stress. Journal of Neuroscience, 27(11), 2781-2787.

Cherniss, C. (1980). Staff burnout: Job stress in the human services. London: Sage Publications.

Cooper, C., Liukkonen, P., \& Cartwright, S. (1996). Stress prevention in the workplace. Luxembourg: Office des publications officielles des communautés européennes.

D’Zurilla, T., \& Nezu, A. (1990). Development and preliminary evaluation of the Social Problem-Solving Inventory. Psychological Assessment, 2(2), 156-163.

Edries, N., Jelsma, J., \& Maart, S. (2013). The impact of an employee wellness programme in clothing/ textile manufacturing companies: A randomised controlled trial. BMC Public Health, 13(1).

Grawe, K. (2004). Psychological therapy. Ashland, OH, US: Hogrefe \& Huber Publishers.

Greenberger, D., \& Padesky, C. A. (1995). Mind over mood: A cognitive therapy treatment manual for clients. New York, NY, US: Guilford Press.

Harkin, B., Webb, T., Chang, B., Prestwich, A., Conner, M., \& Kellar, I. (2016). Does monitoring goal progress promote goal attainment? A meta-analysis of the experimental evidence. Psychological Bulletin, 142(2), 198-229. 
Harnois G., \& Gabriel P. (2000). Mental Health: Issues, impact and practices. Geneva: World Health Organisation, 5 .

Harvey,, A., Watkins, E., Mansell, W., \& Shafran, R. (2004). Cognitive behavioural processes across psychological disorders: Atrans diagnostic approach to research and treatment.

Hiltunen, A., Kocys, E., \& Perrin-Wallqvist, R. (2013). Effectiveness of cognitive behavioral therapy: An evaluation of therapies provided by trainees at a university psychotherapy training center. Psych Journal, 2(2), 101-112.

Hofmann, S., Asnaani, A., Vonk, I., Sawyer, A., \& Fang, A. (2012). The efficacy of cognitive behavioral therapy: A review of meta-analyses. Cognitive Therapy and Research, 36(5), 427-440.

Hofmann, S., Asnaani, A., Vonk, I., Sawyer, A., \& Fang, A. (2019). The efficacy of cognitive behavioral therapy: A review of meta-analyses.

Holtforth, M., \& Castonguay, L. (2005). Relationship and techniques in cognitive-behavioral therapy: A motivational approach. Psychotherapy: Theory, Research, Practice, Training, 42(4), 443-455.

Johnstone, L., \& Dallos, R. (2006). Formulation in psychology and psychotherapy: Making sense of people's problems. Routledge.

Lagerveld, S., Blonk, R., Brenninkmeijer, V., Wijngaards-de Meij, L., \& Schaufeli, W. (2012). Workfocused treatment of common mental disorders and return to work: A comparative outcome study. Journal of Occupational Health Psychology, 17(2), 220-234.

Leitão, S., \& Greiner, B. (2015). Organisational safety climate and occupational accidents and injuries: An epidemiology-based systematic review. Work \& Stress, 30(1), 71-90.

Madill, P. (2017). The power of cognitive behavioural techniques in the workplace.

McEwen, B. (2000). The neurobiology of stress: From serendipity to clinical relevance. Published on the World Wide Web on 22 November 2000. Brain Research, 886(1-2), 172-189.

McEwen, B. (2017). Neurobiological and systemic effects of chronic stress. Chronic Stress, 1, 247054701769232.

Mental Health at Work: Developing the Business Case I ENMHP. (2019). Retrieved from http://www. mentalhealthpromotion.net/?i=portal.en.bibliography .985

Ministry of Health, Labour and Welfare (2013). Occupational safety and health, special investigation. Laborer Health Survey.

Needleman, L. (1999). Cognitive case conceptualization. Mahwah, N.J.: Erlbaum.

Pratt, L. (2009). Serious psychological distress, as measured by the K6, and mortality. Annals of Epidemiology, 19(3), 202-209.

Rao, S., \& Ramesh, N. (2015). Depression, anxiety and stress levels in industrial workers: A pilot study in Bangalore, India. Industrial Psychiatry Journal, 24(1), 23.

Reme, S., Grasdal, A., Løvvik, C., Lie, S., \& Øverland, S. (2015). Work-focused cognitive-behavioural therapy and individual job support to increase work participation in common mental disorders: A randomised controlled multicentre trial. Occupational and Environmental Medicine, 72(10), 745-752.

Richardson, K., \& Rothstein, H. (2008). Effects of occupational stress management intervention programs: A meta-analysis. Journal of Occupational Health Psychology.

Robinson, A. (2009). Dangers of diagnostic labels in patients with mental health issues. Progress in Neurology and Psychiatry, 13(5), 6-7.

Srivastava, K. (2009). Mental health and industry: Dynamics and perspectives. Industrial Psychiatry Journal, 18(1), 1. 
Stelling, J., \& Cherniss, C. (1982). Professional burnout in human service organizations. Contemporary Sociology, 11(1), 105.

Takechi, S., Kikuchi, T., Horisawa, S., Nakagawa, A., Yoshimura, K., \& Mimura, M. (2015). Effectiveness of a cognitive behavioral therapy-based exercise program for healthy employees. Advances in Physical Education, 05(04), 263-272.

The Sainsbury Centre for Mental Health, The Future of Mental Health: a Vision for 2015. Retrieved from https://www.centreformentalhealth.org.uk/sites/default/files/mental_health_futures_policy_ paper.pdf

Weinberg, A., \& Doyle, N. (2017). Psychology at work: Improving wellbeing and productivity in the workplace. The British Psychological Society.

Weissman JF, e. (2019). Serious psychological distress among adults: United States, 2009-2013. PubMed - NCBI. Retrieved from https://www.ncbi.nlm.nih.gov/pubmed/26046826 